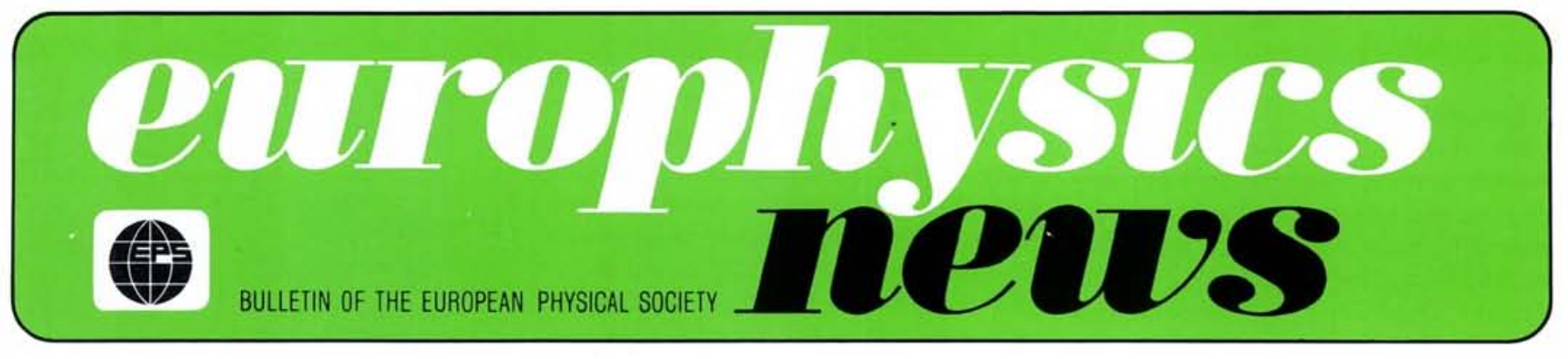

\title{
Highlights from Helsinki
}

\section{7th General Conference: a Meeting of Superlatives}

Organisers of conferences cannot invent new physics for the occasion, but they can perceive the exciting trends and then choose speakers able to explain in clear language what is going on. And this is what Professor Dransfeld and his International Programme Committee had done for Helsinki. As he himself said in the opening session, "the changes that have taken place in physics since the last General Conference are quite amazing, as much in traditional fields as in the frontier discoveries". Helsinki was a rare opportunity at one stroke to gain insight into all today's key development areas. The clarity of the plenary talks was exceptionally high: almost all the plenary speakers made the effort to address themselves to a non-specialist audience and the time-keeping was impeccable.

As with every General Conference, there are many who will in one breath declaim the necessity for broadening their horizons from time to time by seeing into other disciplines, and in the next declare themselves too busy to do other than attend topical conferences in their own subject. So it was with Helsinki, but the nearly 800 participants who made the journey, returned inspired by their experience and enthused by what they had heard. The Proceedings will be a collector's item.*

The University of Technology is truly an ideal location for a conference of this size. A generously laid out campus surrounds a central building housing a main auditorium and several conference rooms of different capacity, all superbly equipped for projection. Moreover the Local Organising Committee under Professor Lounasmaa had made a great effort to cater for all tastes (and pockets, as far as they could in this expensive city) and in the entrance hall a bevy of young and willing helpers were always on hand. The weather could have been kinder, particularly to the campers occupying the 60 and more tents that were pitched on the campus, but it was fair enough to work in.

A much appreciated innovation was the beer party for the young people on the opening night. After reflexion it was decided to reserve this entirely to young people rather than try and mix in some of the more mature and this policy won general approval. The evening was the time to make acquaintance with contemporaries from different lands; there would be ample opportunity during the breaks in the sessions to button-hole the big names. An added reason was that the place where the party was held could only just accommodate all the young people who came. A good number of young Finns, of course, but also 155 young people who had received grants from the EPS with money provided from the Young Physicists Fund and from the local organizers.

Another innovation was the admission of "general" posters. In addition to the posters directly associated with the Special Symposia, which were set up in the wide corridors close to the relevant conference room and consequently well patronised, space was given for posters on any subject of a general interest. Not vigorously advertised as the organisers feared a flood, it was nevertheless well supported and brought the total number of posters to 141 .

The wide spaces around the main auditorium provided an excellent site for the 26 stands that made up the industrial exhibition. A wide range of equip-

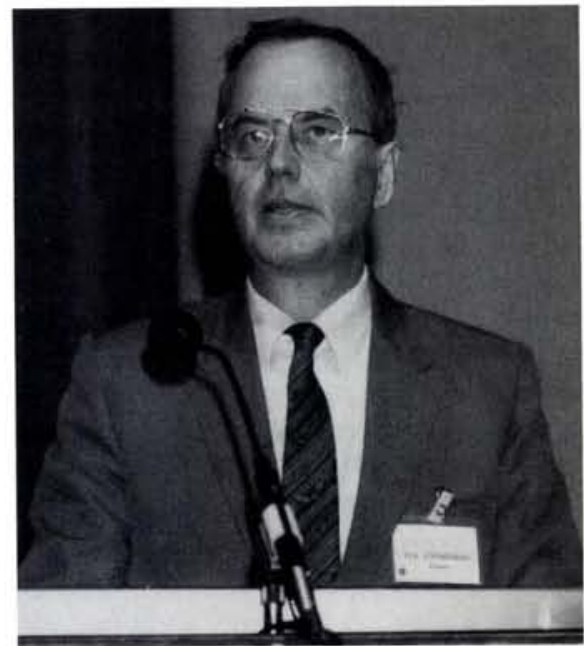

Fig. 1 - O.V. Lounasmaa, Chairman of the Local Organising Committee at the opening session.

ment (particularly vacuum) was on show and most exhibitors seemed well pleased with the business they were able to do. - Copies of the Proceedings of the 6 th General Conference,
Prague 1984, are still available from the Secretariat, price 30.- SFR.

\begin{tabular}{ll} 
Contents & \\
Helsinki & 109 \\
$\quad$ Physics Review & 110 \\
$\quad$ General Meeting & 114 \\
Divisional News & 115 \\
New EPS Members & 115 \\
$\begin{array}{l}\text { Comparative Evolution } \\
\text { of the Atmospheres } \\
\text { of Giant Planets }\end{array}$ & \\
$\begin{array}{l}\text { The Gyrotron } \\
\text { Joint Prizes in } \\
\text { Physics 1987 }\end{array}$ & 116 \\
\begin{tabular}{l} 
Next General Meeting \\
\multicolumn{2}{l}{} \\
\hline
\end{tabular} & 120 \\
\hline
\end{tabular}




\section{PHYSICS}

\section{Superconductivity}

Top of the popularity charts was undoubtedly the development of high temperature superconductors and before a crowded house Alex Müller described the reasoning over the years that had led him and J. Bednorz to their experiments on layered oxides of copper with barium and lanthanum. For those interested in the history of physics, this was a rare occasion to follow the arguments streamlined to be sure - that had led to the discarding of traditional wisdom, so opening the door on what must be one of the most dramatic "gold-rushes" in physics history. How high have we got? Müller reported that in four separate places now with a Y-Ba-Cu-O mix, superconductivity had been seen at $230 \mathrm{~K}$ as a metastable phenomenon. Later, in the Symposium, Zh. Alferov (reluctantly speaking in the absence of Ossipyan who should have been reporting on work in the Soviet Union) gave the news that with the addition of fluorine $a T_{c}$ of 175 $\mathrm{K}$ had been obtained (reproducibly) at which temperature there was about a $20 \%$ Meisner effect increasing to $100 \%$ as the temperature was lowered towards $90 \mathrm{~K}$. [Incidentally why do most lecturers these days eschew any demonstration? Only after his talk did Müller have the Meisner effect demonstrated - so simple and so effective to see a pellet of material levitate over a magnet when liquid nitrogen was added].

On the theoretical front there may be a slow convergence of ideas but as $P$.

Fig. 2 - So that is what all the fuss is about!

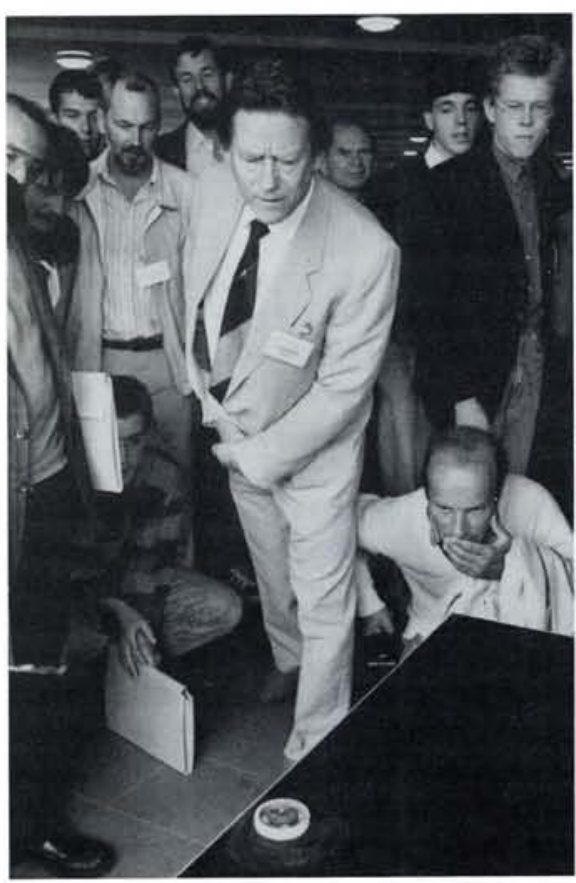

Fulde insisted, following his review of the present state, no microscopic theory at the present time allows you to calculate $T_{c}$. Also it was worth remembering that 45 years passed between the discovery of the phenomenon of superconductivity and the elaboration of the standard BCS theory based on coupling between electrons of opposite spins attributed to phonon exchanges. Theorists needed a little more time to arrive at a consensus or even have opinions on the different models put forward. For the present it seemed that the new superconductors were all "hole" superconductors and that the flux quantum was $h c / 2 e$ which indicated a pairing phenomenon. K. Fossheim concludes from the results of sound velocity measurements exploring the elastic properties, that the lattice is definitely involved. These superconducting materials soften before $T_{c}$ is approached and have a special behaviour below. I. Yanson, the winner of the 1987 Hewlett-Packard Europhysics Prize (which was formally presented after the EPS General Meeting, q.v.), underlining the way in which different areas of physics develop together, referred to recent experiments using pointcontact spectroscopy. These seemed to give direct evidence for electron-phonon interaction, but there could be other interpretations of the effects observed such as them being due to the granular nature of the material. De Gennes in contrast to his more cautious colleagues was keen to explore the "chemical" approach of considering the copper oxide couplings between ions providing a strong Coulomb force and the interatomic forces, involving perhaps $\mathrm{Cu}^{3+}$, as well as canted phases. All agreed that the subject was in its infancy and there was a great challenge to the experimentalists to produce consistent well-characterised samples - before the world dashed into making plans for putting up superconducting power lines.

\section{Supernova}

Human ingenuity can invent new materials and new spectroscopic techniques but it cannot order a supernova explosion in a nearby galaxy as occurred on 23 February this year. Although some ten new supernova events are observable each year in distant galaxies, the frequency to be expected in a system as near as the Large Magellanic Cloud is about once in 500 years. Because of the modern concentration of telescopes in the southern hemisphere and the particular interest in the Magellanic Clouds, observations on the phenomenon began within an hour or so of the first light

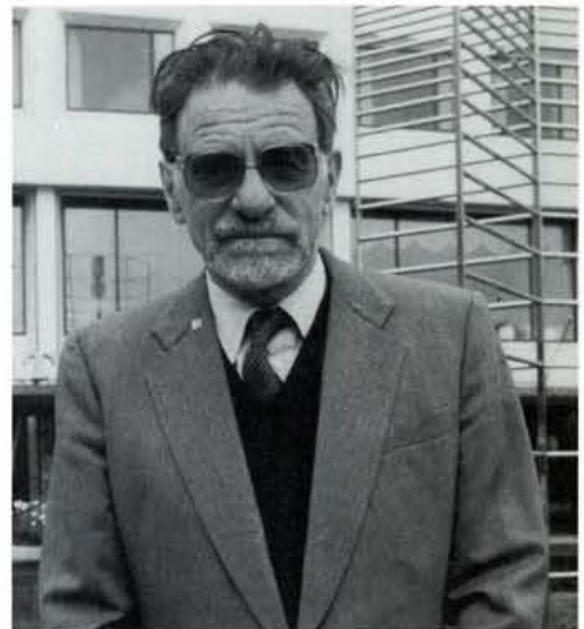

Fig. 3 - And the man who with J. Bednorz started it all - Alex Müller.

reaching us. But even before that, the signature of what is now referred to as $\mathrm{SN} 1987 \mathrm{~A}$ had been registered in the pulse of neutrinos recorded in different laboratories. Following the collapse of the core (in about $10^{-2} \mathrm{~s}$ ) and the subsequent bounce which results in the break up of the star and the ejection of the outer layers, the luminosity rose over the course of several hours to about $10^{10}$ times that of the Sun and slowly increased over the next 80 days. Not as spectacular as some of its predecessors in regard to the maximum luminosity, its characteristics seem to fall somewhere between the classic Type I and Type II supernovae. Type I are stars which have lost through the action of the solar wind their envelope, whereas Type II have retained it up to the moment of the explosion (F.-K. Thielemann, Europhys. News 16 (1985) July/August). All the data obtained up to now, L. Woltjer explained, pointed to the explosion of a star that had previously lost most of its envelope but not all and they confirmed the "onion layer" model of supernova evolution.

The neutrino bursts recorded at Cleveland in the USA and Kamioka in Japan correspond in time and number with the spectral observations (incidentally putting an upper limit of $30 \mathrm{eV}$ on the neutrino mass) and so far the behaviour generally has followed expectations. It has yet to be seen whether this will continue, but it is now becoming possible to measure the element abundances in the expanding blaze and soon the neutron star that remains will show itself through the blanketing haze. Still unresolved is the reason for the neutrino activity recorded in the Mont Blanc detector some hours too early and this may remain a mystery. What is certain is that this bright new neighbour will be a centre of attention for many years to come. 


\section{Super Visitor}

Another regular centre of attention once every 76 years - is Halley's comet. Not all the data collected in notably the Giotto and Vega missions have yet been analysed, but already a remarkably intimate picture of this periodic visitor has been built up. J. Geiss while summarising its main characteristics showed a film of the $70 \mathrm{~km} / \mathrm{s}$ fly-to, obtained by putting together shots taken over many hours. And very impressive it was. The nucleus measures some $16 \times 8 \times 8 \mathrm{~km}^{3}$ and has a volume of $550 \mathrm{~km}^{3}$. The mean density is low $\left(0.1-0.3 \mathrm{~g} / \mathrm{cm}^{3}\right)$ and the escape velocity is about $2 \mathrm{~m} / \mathrm{s}$. It has a rotation period of 7.4 days and a nutation period of 2.2 days. The albedo is low indicating a very "dirty snowball". Gas production as a result of solar heating is about $21 \mathrm{ton} / \mathrm{s}$, the molecular flow expanding at around $800 \mathrm{~m} / \mathrm{s}$. Protected from the solar wind inside the contact surface (where the 60 $\mathrm{nT}$ magnetic field has dropped to zero some $5000 \mathrm{~km}$ from the comet) the temperature is $200-300 \mathrm{~K}$ and photochemistry and ion molecule reactions dominate leading to a preponderance of $\mathrm{H}_{3} \mathrm{O}^{+}$ions. Gas density at $2000 \mathrm{~km}$ is 2 $\times 10^{7} \mathrm{mols} / \mathrm{cm}^{3}$. Some $80 \%$ of the gas emitted by the nucleus is water, a goodly fraction is $\mathrm{CO}, \mathrm{CO}_{2}$ and $\mathrm{CH}_{4}$, and there is a surprising amount of $\mathrm{S}$. The dust that is carried along with it is somewhat richer in $\mathrm{C}, \mathrm{H}$ and $\mathrm{S}$ and mass spectrometer readings indicate a significant amount of elements in the 40 and 56 range. Altogether the material emitted is much richer in volatiles than one sees in chondrites. Comet Halley it would seem has had a low temperature history. If there has been a hot period in a body's evolution much of the nitrogen goes into $\mathrm{NH}_{3}$ whereas if the material stays cold it remains as $\mathrm{N}_{2}$. Both $\mathrm{N}$ and $\mathrm{H}$ are depleted and the relative abundances indicate little heating. It is inferred that Comet Halley did not condense from the solar nebular cloud but from the interstellar medium and chemical synthesis was at low temperature.

On one round trip, the comet loses a 6 $\mathrm{m}$ layer averaged over the whole surface, so generations of astronomers to come will have the opportunity to compare their data with what has been acquired on these super-successful space missions.

\section{Super Small and Super Strings}

Astrophysics is much concerned with reaching back in time, back through nuclear physics to particle physics and $K$. Kajantie reported on new efforts to study experimentally the Universe when

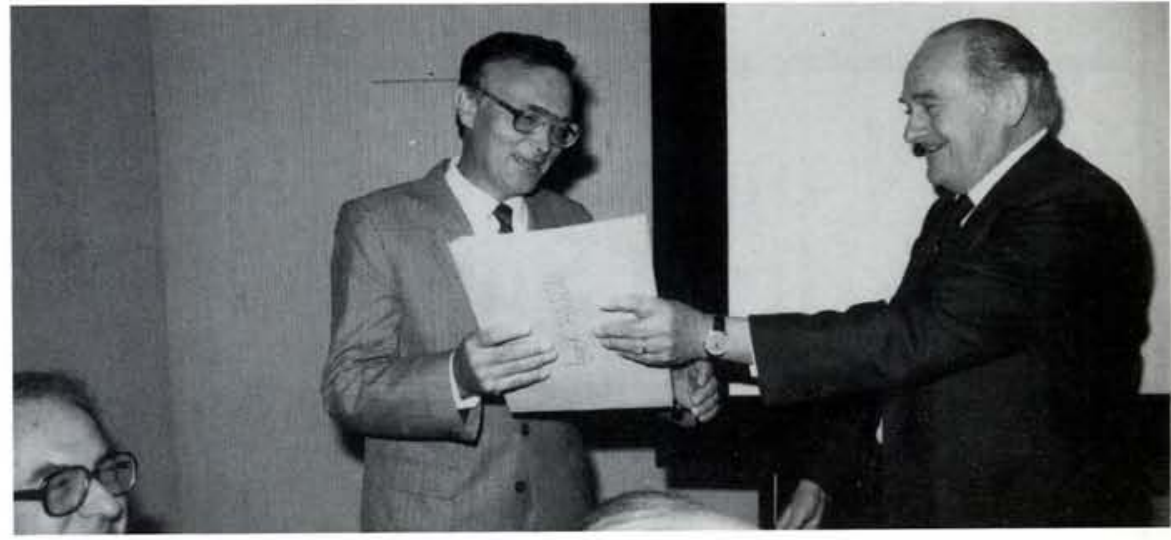

Fig. 4 - The EPS President (right) W. Buckel presents the 1987 H.-P. Europhysics Prize to I.K. Yanson for his work on point-contact spectroscopy (EN, 18 (1987) 21) while A. Mackintosh, Chairman of the Selection Committee (left) looks on. (All photos, Lehtikuva Oy, Helsinki).

it was from 8-15 $\mu$ s old, about $10 \mathrm{~km}$ across and expanding at a constant temperature of around $200 \mathrm{MeV}$. This was the period when the quarks and gluons which had formed a colour plasma went through a phase transition and were confined into nucleons, pions and other hadrons. Such conditions would seem to be pretty inaccessible, but through "little bangs" it is hoped to be able to infer what went on. First experiments were made at CERN in November of last year with a beam of oxygen of energy $3200 \mathrm{GeV}$ striking a high Z target and shortly beams of sulphur ions will become available to push the centre of mass enery still higher. Plans for beams of lead ions are in hand.

How does gravity fit in? M. Green did his best to get us to understand the multidimensional world of superstrings which have an average length of $10^{-35}$ $\mathrm{m}$, the point where Einstein's theory of relativity has severe problems in incorporating quantum mechanics as it leads to a space peppered with black holes. String theory is still not at a state where it can predict anything at our sort of energies - all the particles we know can be considered massless at the scales envisioned - so it seems we have a little time to grapple with the conceptual difficulties the theory poses.

\section{Super Hot}

Against this sort of background, the idea of creating little suns in the laboratory seems almost prosaic, but although JET has been a remarkable European success from a machine point of view, none who heard R. Bickerton summarising the results to date would be led into believing that plasma confinement was easy. Central to the fusion community's objectives was to fulfil the Lawson criterion: for a contained plas$\mathrm{ma}$ at an ion temperature of $10 \mathrm{keV}$, density $\times$ energy confinement time $\geq 2 \times$
$20 \mathrm{~m}^{-3} \mathrm{~s}$. Theories abound to explain the degradation of confinement time with energy input that is found in practice as more additional heating is added, and the only reliable guide at present seemed to be that for a tokamak plasma contained in closed magnetic surfaces, the Golston scaling rule applied: $\tau_{\mathrm{e}}(\mathrm{s})=$

$3.7 \times 10^{-2} I_{p} P^{-1 / 2} R^{1.75} a^{-0.37}(b / a)^{1 / 2}$ where $I_{p}$ is the plasma current, $P$ input power, $R$ the major and $a$ the minor torus radii, and $b / a$ the elongation. This seemed to fit the JET results for currents of 1-5 MA. By putting a null point in the outer magnetic field shell to produce "H-mode" operation [F. Wagner, Europhys. News 17 (1986) 48] a gain of a factor 2 was obtained but degradation with increasing power was still observed. Nevertheless, operating in deuterium gas and with $6 \mathrm{MW}$ additional heating, a temperature of $12 \mathrm{keV}$ had now been reached. Were a tritium/deuterium mixture to be used in JET, it is calculated that a $Q$ (thermonuclear power / power input) of 0.1 could be attained and that with present enhancements which will take the current to $7 \mathrm{MA}$, a $Q$ of 1.0 might be achieved in 1992. From this, the NET team looking at the Next European Torus was concluding that in a machine with $R=5.4 \mathrm{~m}, B_{\mathrm{T}}=4.8 \mathrm{~T}$, a $=1.7 \mathrm{~m}$, at a current of $15 \mathrm{MA}$, the plasma should be able to ignite. There is a lot more physics to be done however before we are there.

\section{Super Nuclei and Atoms}

JET is far from alone in being a European experiment with the highest world performance. GSI at Darmstadt is unique in its capability of being able to accelerate intense beams of uranium ions up to energies of $8 \mathrm{MeV} /$ nucleon. The main focus of research there is on positron spectrometry of quasi atoms. Electrons can bind to the compound nuclei 
International Symposium on the

\section{TECHNOLOGIES FOR OPTOELECTRONICS}

16-20 November 1987

Palais des Festivals et des Congrès Cannes, France

\section{Symposium Chair:}

Erich Spitz, Thomson-CSF (France)

\section{Organized by}

ANRT-Association Nationale de la

Recherche Technique

SPIE-The International Society for Optical Engineering

\section{Cooperating Sponsors}

Associazione Elettrotecnica ed Elettronica Italiana • Austrian Physical Society •

Battelle-Geneva Research Centres - Comité Belge d'Optique • European Physical

Society in collaboration with its Optics

Division • Israel Laser and Electro-Optic

Society $\bullet$ Optics Division/Portuguese

Physical Society - Promoptica - SEE-

Société Francaise des Electriciens, des

Electroniciens et des Radioélectriciens • SGOEM-Schweizerische Gesellschaft für

Optik und Elektronenmikroskopie • Sira

Ltd. - The Research Association for

Instrumentation • Société Française d'Optique

\section{NINE CONFERENCES}

Presenting over 240 Technical Papers

Quantum Wells and Superlattices in Optoelectronic Devices and Integrated Optics

Real Time Image Processing: Concepts and Technologies

Materials and Technologies for Optical Communications Devices

Focal Plane Arrays: Technology and Applications

Optical Devices in Adverse Environments

Advanced Optoelectronic Technology

Optical Interconnections

Optoelectronic Technologies for Remote Sensing from Space

Industrial Optoelectronic Measurement Systems Using Coherent Light

\section{TUTORIAL SHORT COURSES} TECHNICAL INSTRUMENT EXHIBIT

For complete program and exhibit information, or to order Proceedings related to or resulting from these conferences, in Europe contact: ANRT, 16. Avenue conferences, in Europe contact. ANRT, 16, Avenue 53-2667. Telex 642632 , France: Telephone: (33) 1.45. 53-2667; Telex 642632. Or contact SPIE-The International Society for Optical Engineering. Avenue de la Tanche 2, B-1160 Brussels, Belgium; Telephone: 2 660.45 .11 . Telex 25387 AWAL B. In North America 0010; Telephone: 206/676-3290; Telex 46-7053. formed in collisions to produce quasi atoms. These can eject high momentum electrons and if $Z>173$ (when the binding energy $>2 m_{0} c^{2}$ ) positrons can be created.

P. Kienle in describing the latest results was very careful not to claim the "discovery" of a new neutral particle of mass $3 m_{\mathrm{e}}$ but they had strong evidence that such particles were formed which decayed into $\mathrm{e}^{+} \mathrm{e}^{-}$pairs. Experiments are very difficult and need intense beams because the events are rare. $\mathrm{Ne}$ vertheless, whilst the continuum spectrum can be deduced theoretically with good accuracy, the lines found around $300 \mathrm{keV}$ stand out. In sub-critical systems too, lines have been identified at $250 \mathrm{keV}$ and 350/400 keV. No suggestion of a new group of leptons was, however, heard.

Nor was any claim made to glimpsing the holy grail inside these atoms such as Niels Andersen, in what was perhaps the most polished of all the presentations, suggested was possible in the socalled "perfect scattering experiments". The study of atomic shapes and rotation has recently become a fruitful area for confronting theory with experiment. Quite simple techniques involving the bombardment of a target by low energy atoms and measuring in coincidence the scattered photons or electrons allows one to study the results of changing the shape and rotation of the atomic cloud and give a "direct" visualisation of its shape and dynamics.

Against the sensational background of superconductivity, supernovae, superstrings etc., it was fascinating to see how much novelty there was in even topographical subjects. D. Schechtman described the quasi-crystals and the traditionally forbidden five-fold symmetry that had been found now in some 25 alloys, while de Gennes gave us the impression that a lot of our life was tied up with the physics of suspended grains. His central theme was polymers at interfaces and he led us along the paths of progress in our understanding of such phenomena as the morphology of polymer chains on absorbing sites which gives rise to self-similar fluffy structures. Fascinating also to hear a theoretician from academia calling for more people to enter the field because of its great industrial importance, not least to study bridging between grains that is exploited, for example, in water purification by floculation.

\section{Supercomputers}

Computers are, of course, ubiquitous these days and we were treated to two reviews. The first by $A$. Lohmann sang the praises of optics for superparallel computing although he ingenuously admitted at the end that we were still a little way from commercial application. About the long-term, however, he had no doubts. T. Regge in presenting the Cecil-Powell Memorial lecture chose to discuss computer algebra from the vital necessity for collaboration in creating systems and defining the notation and general approach. Computer algebra was a growing activity that would require a lot of computer power if a system was to have the necessary flexibility. Currently each system was different, very user unfriendly while the manuals provided seemed to be designed solely for people who already knew the system intimately.

\section{Super Techniques}

Measurement techniques are, of course, continually evolving and it was astounding, following on from Yanson's Hewlett-Packard lecture on point-contact spectroscopy, to hear H. Rohrer's review of the developments that had taken place in the application of the scanning tunnelling microscope. Since Prague when Binnig described the new

\section{L'UNIVERSITÉ DE LAUSANNE}

ouvre une inscription pour la pourvue d'un poste de

\section{professeur ordinaire (full professor) en physique expérimentale de la matière condensée}

Entrée en fonction: 1.11 .1988 ou à convenir.

Le titulaire du poste devra participer aux tâches d'enseignement de I'Institut de physique expérimentale (I.P.E.) en physique générale et en physique du solide.

Pour réaliser son programme de recherche, il pourra disposer de l'infrastructure de l'Institut (installations pour l'obtention de basses températures et de champs magnétiques, installations de métallurgie (couches minces), centre de micro-analyse, ...).

Renseignements complémentaires auprès de I' I.P.E.,

prof. L. Rinderer, prof. R. Huguenin, BSP, 1015 Lausanne.

Les candidatures (avec curriculum vitae et liste de publications) doivent parvenir avant le 30 novembre 1987 à

M. prof. M. GAILLOUD,

Doyen de la Faculté des Sciences, CH - 1015 Lausanne. 
invention, the STM has not only found application in a wide range of fields but the method has been extended so that changes in voltage, in current and in polarity are all used to give new information on surface structures. Pictures were shown for example of a GaAs surface where with one polarity only the $\mathrm{Ga}$ atoms are visible and with the other, only the As atoms. We saw maps of charge density waves, heard of electrochemical experiments, watched diffusion processes, identified electron traps, saw how elastic properties could be measured... Moreover the device is not limited to the atomic scale. It is already being used in biophysics for DNA studies, for example; one wondered how it was ever possible to do physics without it.

Space and capacity prevent our doing justice to the other plenary lecturers (although we hope to cover most of their topics in due course): S. van der Meer talking on the problems to be mastered for the next generation of $\mathrm{e}^{+} \mathrm{e}^{-}$supercolliders, J. Als-Nielsen on the study of liquid surfaces using synchrotron radiation, F. Arecchi on chaos in lasers, T. Kohonen on physical models of the brain and $\mathrm{N}$. Bloemberger reviewing the APS study on directed energy weapons which concluded that it was too early to form any real opinion on their feasibility. We also can only mention the seemingly unanimous satisfaction with the 15 scientific symposia that had been arranged.

\section{Not So Super Education}

However, we should perhaps not neglect the universal topic of physics education. B. Pippard felt there was no new wisdom to impart on education policy, but a lot of old wisdom to apply. Universities have a duty to inspire as well as instruct and students looking back on their university life should feel that they also learned something about life as well.

He saw it as a matter of urgency that an influential body of people should foresake the laboratory - not everyone at University can do research - and study how better to teach physics and disseminate information on it. Otherwise the Universities will revert to their "natural state of a supine acceptance of the status quo". He strongly advocated challenging students to think as against simply storing knowledge and he fascinated his audience with a short glass rod, slightly bowed that would spin happily in one direction but would go into convulsions if spun in the other, before reversing its direction. Confronted with this clear violation of the conservation of angular momentum his audience had no immediate conclusions to offer.

In the somewhat ragged panel discussion on physics in schools that followed, perhaps the most concrete conclusion - although by no means unanimous was the virtue of pressing simply the need for science to be taught and trying to mobilise the whole of scientific opinion rather than urge that special consideration be given to our own particular discipline. Perhaps more general was the feeling that physics had to be made interesting - it could be fun and serious at the same time and the necessity to inculcate facts did not exclude giving insight into how science works. The tendency today was to teach science as a set of rules which had very little to do with the realities of everyday life.

Decoupling school teaching from university entrance altogether was felt to be too revolutionary, but it was generally admitted that the universities still exercised, through the competition in a few specialist subjects, a deadening hand on any broadening of the education syllabus. This applied to arts students as much as to those reading science.

Physics it has to be acknowledged is not an easy subject and in his valedictory message at the end of the Conference, the President had this to say, to the younger physicists who complained that they did not understand all they had heard - in brief: "Neither did I" (and could have added and nor did anyone else). Noone can expect to absorb instantly new and complex ideas when they hear them for the first time however well they are explained.

\section{Special Symposia}

Despite being held in the evening, the three special symposia on "Nuclear Winter", "Employment", and "Physics in Developing Countries" were well supported. The EPS reports on the first two subjects which have already been summarised in these pages (May and June 1987 respectively) were presented, the first with its grim message that there would be "no shelter" in the event of a nuclear war and the second with the optimistic conclusion that the job market for physicists was rather satisfactory (even if there were a few skeptics). In the third a series of papers was given outlining the problems of forming a scientific infrastructure in developing countries and the Chairmen of the Interdisciplinary Group on Physics for Development, E. Lillethun, made an appeal for more members to join the Group and to bring their ideas for cooperative help.

\section{General Meeting}

Once every three years those Ordinary Members who are able to do so come together for the General Meeting. Coinciding on this occasion with Schrödingers 100th birthday (and Dransfeld's much less) over 100 members were present when the President opened with his report. He referred in particular to the great success of Europhysics Letters which had far exceeded in popularity as a publishing medium the most optimistic expectations. A consequence was a short-term financial deficit, as subscription rates had been based on a much smaller number of pages per volume, and this had decided the management to call in the guarantee capital that various national societies had placed on deposit. A new partnership agreement was being drawn up which would have the effect of bringing in these societies as full partners. For the future, volumes would be standardized and their frequency tailored to the demand. The journal should then quickly reach the breakeven point. Members had, however, the responsibility to see that their own libraries were subscribers as the list was still well short of the potential.

As seems to be normal, the general finances of the Society are not too comfortable and as a minimum operation it will be necessary to increase the unit fee in 1989 to keep pace with inflation. We have the perennial problem of nonpaying members and while the computerisation of the lists makes easier the operations of reminding and finally striking off, the wastage is up to $20 \%$ per year so that in order to remain static, steady recruitment is necessary. Again members can help by encouraging their colleagues to join (and pay!). This is really the only way of keeping up the momentum; the different ways of coliecting fees have all been explored, but our multinational composition imposes severe limitations in practice.

A number of familiar themes were raised - a bigger Europhysics News, a Council meeting at the time of the General Conference, the promotion of E-W relations and its importance beyond the Society and then a brief discussion was held on the General Conference itself. Join it to a Divisional Conference; have no other Divisional meetings the same year. No conclusions were drawn and the President invited Members to write to him with their ideas on this subject.

Finally we had a swift pictorial travelogue of Amsterdam to whet our appetites for the 8th General Conference to be held there from 4-8 September 1990. What is better than Super? 